Dossiê: Conferência de Medellín: 50 anos - Artigo Original (c) (1)

\title{
¿Una exaltación de lo empírico? La metodología teológico- pastoral de Medellín en debate
}

\section{An exaltation of the empirical? The theological-pastoral methodology of Medellín in debate}

\author{
Carlos Schickendantz*
}

\begin{abstract}
Resumen
La metodología teológico-pastoral, que configuró no solo los textos sino la dinámica de trabajo de Medellín, tuvo en la década del sesenta importantes desarrollos y debates. La presente contribución se concentra, particularmente, en una crítica radical a dicha Conferencia formulada entonces por Eduardo Briancesco. Primero, presenta las objeciones del teólogo argentino, quien afirma que hay en Medellín una exaltación indebida de lo empírico. En segundo lugar, el artículo realiza una evaluación de la posición del autor, prestando atención, de forma particular, a algunos aspectos importantes del estado de la cuestión en el debate metodológico de entonces. De esta manera se contextualiza mejor la crítica y también se comprenden más adecuadamente algunos logros y limitaciones de la obra de Medellín desde el punto de vista de la metodología teológica.
\end{abstract}

Palabras-clave: ver-juzgar-actuar; signos de los tiempos; método inductivo.

\begin{abstract}
The theological-pastoral methodology, which configured not only the texts but the work dynamics of Medellín, had important developments and debates in the 1960s. This contribution is concentrated, particularly, in a radical critique of the Conference made by Eduardo Briancesco. First, its presents the objections of the Argentine theologian, who affirms that there is an undue exaltation of the empirical aspect in Medellín. Second, the article makes an assessment of the author's position, paying attention, in particular, to some important aspects of the state of the question in the methodological debate at that time. In this way, the criticism is better contextualized and some achievements and limitations of the Medellín works are more adequately understood from the point of view of the theological methodology.
\end{abstract}

Keywords: see-judge-act; signs of the times; inductive method.

Artigo recebido em 15 de maio de 2018 e aprovado em 28 de agosto de 2018

*Doctor en Teología por la Universidad de Tübingen, Alemania. Académico e investigador del Centro Teológico Manuel Larraín, Universidad Alberto Hurtado (Chile). País de origem: Chile. E-mail: carlosschickendantz@gmail.com

Horizonte, Belo Horizonte, v. 16, n. 50, p. 517-543, maio/ago. 2018 - ISSN 2175-5841 


\section{Introducción}

La novedad e importancia de la metodología teológica adoptada en la Conferencia de Medellín, particularmente su atención a la realidad históricocontextual gracias al momento inductivo, no pasó inadvertida para los protagonistas de entonces, ni para aquellos más directamente implicados, tampoco para otros que pueden calificarse como observadores o lectores del acontecimiento. Por ejemplo, en marzo de 1969 Gustavo Gutiérrez escribía:

El lenguaje empleado en los textos de Medellín puede sorprender. No estamos en verdad acostumbrados a ver al magisterio de la Iglesia empuñar tan firmemente la realidad, seguirla tan de cerca, emplear los mismos términos que usa todo el mundo para hablar de ellas. Pero es que el primer momento en el discernimiento de los signos de los tiempos es verlos tal como se presentan a los ojos de los hombres de hoy. Es una condición de veracidad. No hacerlo es viciar el proceso desde el inicio. (GUTIÉRREZ, 1969, p. 14)․․

Tenía razón Gutiérrez, en aquel momento nadie estaba "en verdad acostumbrado" a este tipo de discurso por parte del magisterio; solo unos pocos años antes el Vaticano II había introducido con muchas dificultades esta novedad metodológica en la Constitución pastoral, por primera vez en la historia de la Iglesia en un documento conciliar.

No faltan testimonios calificados sobre la importancia de la metodología que destacan, al respecto, la peculiar recepción del Vaticano II en nuestro continente, el progreso verificado en Medellín en comparación con el Concilio, su carácter decisivo para convertir a dicha Conferencia en una carta de identidad de las iglesias de estas tierras, en un antes y después en la historia eclesial de este continente, en sus repercusiones y efectos en los más diversos campos de la pastoral y la teología en los años siguientes ${ }^{2}$. Varias de las experiencias eclesiales más peculiares de

\footnotetext{
1 “Las Conclusiones de la Segunda Conferencia reflejan el deseo de enfrentar con franqueza y decisión los interrogantes y problemas del momento, de escuchar humildemente lo que el Señor quiere decirnos a través de los acontecimientos, de interpretarlos a la luz de la fe. Pero reflejan también una voluntad de compromiso. Los signos de los tiempos no son solo en efecto, una llamada a la interpretación, son también un llamado a la acción: 'La fe opera por la caridad'. La verdad cristiana es afirmación, pero ante todo es obra. 'Obrar la verdad' nos dice un exigente texto evangélico." (GUTIÉRREZ, 1969, p. 14).

${ }^{2}$ Cf. Legorreta (2015, p. 8, 118, 124-125, 137, 167, 171-172, 381, 390, 395, 397 y, muy particularmente, 433-437).
}

Horizonte, Belo Horizonte, v. 16, n. 50, p. 517-543, maio/ago. 2018 - ISSN 2175-5841 
América latina y el Caribe en estas décadas, como la lectura popular de la Biblia, la formación de las comunidades eclesiales de base, la misma teología de la liberación son deudoras de esta forma de proceder que, germinalmente propuesta en Gaudium et spes, configuró completamente la organización y los mismos documentos de la Conferencia de 1968 (BRIGHENTI, 2015, p. 608). La afirmación de José Legorreta, que compartirían muchos autores, es significativa: "el método ver-juzgar-actuar se tornó emblemático de la nueva forma de ser Iglesia y hacer teología en América Latina” (LEGORRETA, 2015, p. 255)3.

En ese marco temático me he detenido en diversas publicaciones: (a) en el estado de la cuestión en la bibliografía internacional acerca de la categoría de signos de los tiempos, expresión simbólica que condensa este tipo de teología (SCHICKENDANTZ, 2016b; 2018); (b) paralelamente he prestado atención al debate metodológico que surgió en la etapa de configuración de Gaudium et spes. Un análisis de los argumentos de entonces muestra con claridad que, a la vista de algunos de los más calificados teólogos de la época, se estaba produciendo una transformación importante en la metodología teológica (SCHICKENDANTZ, 2013, p. 87-101; 2016a; 2018a); (c) también me he ocupado de mostrar el significado de esta forma de proceder para "explicar" el evento de Medellín al analizar los textos oficiales de preparación a la Conferencia y, sobre todo, al revisar el aporte de Marcos McGrath. Debido a la especial responsabilidad del obispo panameño en la etapa final de formación de Gaudium et spes, en sus intervenciones y publicaciones, en especial en las de aquellos años, se visibilizan, quizás mejor que en ningún otro protagonista de Medellín, los logros y los límites del debate metodológico conciliar y su transición hacia el evento de Medellín, con sus nuevas peculiaridades regionales, también con sus logros y limitaciones (SCHICKENDANTZ, 2017a); (d) igualmente he reflexionado sobre la pertinencia

\footnotetext{
${ }^{3}$ Como destaca el autor, se trata de una recepción de la eclesiología de Lumen gentium, pero desde la perspectiva de Gaudium et spes, condición de posibilidad del surgimiento de un nuevo modelo de Iglesia esbozado en Medellín; una maduración de las iglesias locales en el continente. Cf. más detalladamente todavía en Legorreta (2015, p. 432, 435-436). Es ilustrativa la frase allí: "De ahí que la aplicación del método se fuera constituyendo al paso del tiempo en una clave hermenéutica privilegiada para conocer el tipo de recepción conciliar en el continente." (LEGORRETA, 2015, p. 435). Esta perspectiva - una mirada más a histórica y esencialista o una más contextualizada gracias a este método- afecta a todos los temas (modelo de Iglesia, evangelización, inculturación, discipulado, etc.).
}

Horizonte, Belo Horizonte, v. 16, n. 50, p. 517-543, maio/ago. 2018 - ISSN 2175-5841 
de esta metodología de cara a las actuales condiciones culturales de la humanidad marcadas por un pluralismo cultural radical y una diversidad religiosa cada vez más asombrosa y fascinante (SCHICKENDANTZ, 2017b, p. 116-118)4. Estas perspectivas múltiples indican la relevancia, profundidad y complejidad del asunto.

Las referencias a trabajos personales ya publicados tienen el objeto de situar la contribución de estas páginas, que se concentra en un aporte escrito en el tiempo de Medellín del entonces titular de la cátedra de teología moral en la Facultad de Teología de la Universidad Católica Argentina, Eduardo Briancesco. Las observaciones de Briancesco parecen oportunas analizarlas porque, si en su radical criticidad probablemente no recibirían una acogida por parte de muchas personas, ellas reflejan, de un modo elaborado, una perspectiva que, como sospecha permanente y preocupación difusa, ha recorrido las décadas recientes de América Latina cuestionando esta metodología, incluso desde las mismas posturas oficiales, especialmente, en todas y cada una de las Conferencias generales del episcopado latinoamericano posteriores a Medellín (LEGORRETA, 2015, p. 301-302, 304, 339, 371, 374-376, 385). Se trata de una repetida "expresión de resistencia a una racionalidad inductiva e histórica” como ha afirmado Agenor Brighenti (2016, p. 690).

En particular, una de las cuestiones centrales formuladas por el teólogo de Buenos Aires interesa para esta contribución: “¿cuál es la metodología teológica básica, empleada por los redactores del Documento? ¿Cuál es su valor? ¿Cuál su relación con la teología tradicional?” (BRIANCESCO, 1969, p. 225). Las preguntas y la crítica ayudan a no "naturalizar" el cambio en la metodología de la ciencia teológica producido inicialmente en el Vaticano II y decisivo en la configuración de toda la mecánica de trabajo ideada para Medellín y plasmada en sus documentos. Las objeciones de Briancesco expuestas en aquel momento colaboran a aclarar en qué punto específico se observaba un núcleo del asunto en cuestión: una relación diferente entre doctrina y pastoral, especialmente el debate sobre el carácter

\footnotetext{
${ }^{4}$ Los textos de Schickendantz pueden consultarse em: http://uahurtado.academia.edu/CarlosSchickendantz
} 
normativo de los hechos históricos, punto de partida del análisis en los distintos documentos de la Conferencia.

Las críticas del teólogo argentino que se consideran pueden ayudar, también, a imaginar mejor el delicado contexto eclesial de entonces. Al cumplirse los 50 años de la asamblea episcopal de 1968 una celebración "ingenua” apoyada por publicaciones unilateral y superficialmente laudatorias no debería desconocer el complejo y conflictivo panorama eclesial de aquellos años, ni los severos cuestionamientos y perplejidades que el mismo documento de Medellín despertó en aquel momento a pastores, teólogos/as y cristianos/as en general. Además, tampoco parece adecuado pasar por alto sus muchas limitaciones, comprensibles por lo demás. Puede aplicarse aquí la advertencia más general de Silvia Scatena, "como sucede a menudo con los eventos que acaban asumiendo un fuerte valor simbólico y que marcan una época, ha habido una diferencia entre lo que fue efectivamente la asamblea y aquello en lo que se convirtió...” (SCATENA, 2016, p. 279). Soy de la convicción, no obstante, que una lectura serena de los textos de Medellín permite responder adecuadamente a las objeciones de Briancesco, incluso si dichos textos tienen la provisionalidad propia de un documento escrito por centenares de personas en el escaso tiempo de dos semanas, en los meses de agosto y setiembre de 1968.

La presente contribución se desarrolla en dos partes. Primero, sistematiza y presenta las objeciones de E. Briancesco que, desde el punto de vista metodológico, lo inducen a escribir en tono crítico que hay en Medellín una "exaltación (indebida) de lo empírico". En segundo lugar, el artículo realiza una evaluación de la posición del teólogo argentino, prestando atención, de forma particular, a algunos aspectos importantes del estado de la cuestión del debate metodológico de entonces. De esta manera se contextualiza mejor la misma crítica y se comprenden más adecuadamente algunos logros y limitaciones de la obra de Medellín desde el punto de vista de la metodología teológica. 
Una referencia sobre Briancesco5. Poco conocido en el ámbito teológico latinoamericano, en aquel momento él representaba bien una importante línea eclesial y teológica del catolicismo argentino. Para caracterizar su figura ayuda un texto de Lucio Gera en el cual, en 1970, ofrece un panorama sobre la realidad eclesial argentina de entonces:

Producidos los Documentos de Medellín, se dejan entrever las tres típicas reacciones del catolicismo argentino: los grupos tradicionalistas los juzgarán izquierdistas o marxistas; las corrientes liberales los calificarán de clericalistas y en sus líneas más puramente religiosas alertarán ante el temporalismo; los núcleos de protesta social ven en ellos una exigencia de abrirse más decididamente hacia lo nacional y popular. (GERA, 2015a, p. 99).

Como se advierte, Gera distingue en aquel momento tres grupos o líneas eclesiales en el variado mosaico de la Argentina del momento: una posición tradicionalista, conservadora, que llegaba al integrismo en sus formulaciones extremas, con un ideal de cristiandad; la línea del catolicismo liberal, progresista, que buscaba la modernización de la Iglesia -inspirándose particularmente en la renovación teológico-pastoral sobre todo en Francia y Alemania- y que, desde el punto de vista socio-político, asumía las actitudes desarrollistas; una tercera línea es la que denomina en este contexto "la corriente de protesta social", un "catolicismo revolucionario" que, desprendiéndose y criticando en forma cada vez más aguda al sector liberal e, incluso, a la izquierda europea de cuño marxista, desde Medellín progresivamente ganaba terreno. Gera añade poco más abajo:

A partir de Medellín, los conflictos más fuertes se verifican entre la corriente liberal y la de liberación popular. Llama la atención que algunos representantes típicos del progresismo o de la renovación postconciliar, manifiesten escasa o nula simpatía por las Conclusiones de la Segunda Conferencia del Episcopado Latinoamericano. (GERA, 2015a, p. 99; MOYANO, 1994, p. 529-540).

En ese marco eclesial Briancesco es caracterizado en aquellos años como un teólogo progresista, de impronta conciliar, “perteneciente a la corriente liberal de la

\footnotetext{
${ }^{5}$ Un buen panorama biográfico y bibliográfico del autor oferece Galli (2004).
} 
Iglesia argentina" (POLITI, 1992, p. 324), crítico de categorías centrales de la naciente teología del pueblo (pueblo, cultura, etc.), la cual, a su juicio, con una debilidad epistemológica importante, evidenciaba un uso acrítico de nociones y teorías de las ciencias sociales (como dependencia y liberación). En su opinión, estos presupuestos favorecían una temporalización de la fe o subordinación de ella a un proyecto socio-político determinado, esto es, un “cristianismo populista”, un “nuevo mesianismo", poco respetuoso de la autonomía de las realidades temporales y del pluralismo político (POLITI, 1992, p. 316-320; GONZÁLEZ, 2004, p. 43-48, 120-122) ${ }^{6}$. Estas opiniones dirigidas entonces a una corriente teológica en formación -la teología del pueblo- es posible verificarlas, análogamente, en las observaciones de Briancesco a Medellín que se analizan en esta contribución.

Privilegiar la bibliografía de la época de Medellín, como se hace en esta contribución, tiene también un objetivo explícito a partir de una enseñanza reciente proveniente de los estudios dedicados a otro evento, todavía mayor: el Vaticano II. La comprensión del Concilio dio un salto de calidad gracias a las investigaciones dirigidas con el método histórico-crítico, en particular el proyecto que cristalizó en la Historia en cinco volúmenes dirigida por G. Alberigo. Creo que puede decirse que los mejores trabajos hermenéuticos de estas dos últimas décadas sobre el evento conciliar, como los de C. Theobald, P. Hünermann, G. Ruggieri y J. O’Malley, por nombrar solo cuatro especialistas pertenecientes a distintas áreas lingüísticas, están basados en un profundo conocimiento del desarrollo histórico del evento mismo. Encuentro en este punto una indicación precisa en orden a recorrer un camino que colabore al progreso de una comprensión más profunda de la Conferencia de Medellín y su significado para el tiempo posterior7. La constatación de Francisco de Aquino parece una advertencia oportuna: "Llama la atención la ausencia de estudios más desarrollados sobre los 16 documentos de

\footnotetext{
${ }^{6}$ Hasta cierto punto, algunas de las críticas son reconocidas. "La teología del pueblo, por su lado, absolutizó, quizás, el proceso de liberación que parecía llegar a su momento definitorio con el acceso del peronismo al gobierno" en los primeros años de la década del setenta (POLITI, 1992, p. 340).

${ }^{7}$ El trabajo de Silvia Scatena (2007) sigue siendo insustituible.
} 
Medellín, particularmente sobre el documento Justicia”, que él precisamente comenta en una publicación reciente (AQUINO JÚNIOR, 2017, p. 53).

\section{Una exaltación de lo empírico - Eduardo Briancesco}

En el segundo semestre de 1969 el teólogo argentino, Eduardo Briancesco, publicó un extenso artículo sobre el evento de Medellín con el título: “Un caso de teología y pastoral”. Sin la pretensión de ofrecer una definición ya en la primera página de su texto ambas palabras aparecen inicialmente caracterizadas: "la posesión de la Verdad (Doctrina) y su transmisión (Pastoral)” (BRIANCESCO, 1969, p. 188)8 . Este tipo de tratamiento - “un caso de teología y pastoral”- se justifica, argumenta, porque Medellín se sitúa "dentro de la perspectiva abierta por el Vaticano II", un "Concilio Pastoral” que, “de acuerdo a ciertos comentadores, no excluye ni disminuye la dimensión doctrinal” (1969, p. 188).

El planteo -“interacción entre teología y pastoral”- es desarrollado de manera comparativa con ejemplos tomados de los concilios de Trento y del Vaticano I. En el primer caso, argumenta Briancesco, la doctrina del opus operatum se constituyó "de hecho en norma práctica de sacramentalización, es decir de administración sacramental", que trajo aparejado "un descuido u olvido de otros elementos no menos importantes para la recepción concreta del mismo.” La intrínseca eficacia del signo opacó el aspecto tan decisivo de la fe personal en la práctica sacramental. De este modo, piensa el autor, se habría cometido un error fundado en "una identificación o asimilación entre verdad objetiva y praxis concreta”. La “consecuencia” de la "aplicación sin más de la verdad definida” ha conducido en este caso "a una falta de calidad en las exigencias concretas para la administración y recepción del sacramento” (BRIANCESCO, 1969, p. 191).

\footnotetext{
${ }^{8}$ En un texto publicado casi una década después, Briancesco afirma: "Dejando de lado cierto tono polémico, el fondo del análisis nos parece todavía válido, y confirmado por las precisiones posteriores aportadas por el magisterio a la teología de la liberación" (BRIANCESCO, 1977, p. 132, nota 31). Debe advertirse, no obstante, que las observaciones del teólogo argentino en el texto de 1969 se dirigen al mismo documento de Medellín, no a una teología elaborada a partir de él.
}

Horizonte, Belo Horizonte, v. 16, n. 50, p. 517-543, maio/ago. 2018 - ISSN 2175-5841 
En referencia al Vaticano I el hecho de "determinar estrictamente la doctrina, no sólo de la infalibilidad, sino de la potestad ordinaria e inmediata del Romano Pontífice sobre toda la Iglesia, se tradujo, en la praxis eclesial, en un centralismo administrativo de gobierno”, que no se deducía necesariamente de la doctrina conciliar definida. Dicho centralismo "significó una aplicación estricta de una verdad doctrinalmente indiscutible, pero que no podía ni debía tomarse sin matices como norma de acción pastoral.” De manera análoga a lo verificado en relación a Trento, Briancesco observa aquí "un caso más de esa identificación indebida entre doctrina y praxis" (1969, p. 191-192).

El Vaticano II, por el contrario, argumenta Briancesco, no incurre en los errores detectados. No conduce hacia "ningún tipo de identificación abusiva de teoría y praxis, ni en el sentido indicado anteriormente de un sometimiento de la acción a la doctrina, ni -menos aun- en la línea de una subordinación de la teoría a la praxis, como si la realidad práctica y sus exigencias constituyeran de por sí normas adecuadas de acción” (BRIANCESCO, 1969, p. 193). En el Concilio se advierte una posición equilibrada que el autor formula en un sentido positivo de esta manera:

Más allá de las doctrinas, tenemos una norma de evangelización teóricopráctica, consistente en una actitud de apertura leal hacia el mundo en el que, tanto en doctrina como en gestos concretos, el hombre debe reconocer los "signos de los tiempos" (el modo como Dios habla por el mundo de hoy), discernidos e integrados en la corriente vital de la Tradición eclesial plurisecular. (BRIANCESCO, 1969, p. 193).

"Discernir e integrar”, “juzgar y asimilar” en la propia tradición son binomios que Briancesco califica como "capitales" en este contexto (BRIANCESCO, 1969, p. 192-194, 196 nota 5). El autor ilustra esta forma de proceder con ejemplos tomados de Gaudium et spes y Dignitatis humanae. El aspecto positivo que observa en ellos está dado, en el caso de la Constitución pastoral, porque a la luz de la categoría de signos de los tiempos, el documento "detecta algunos de ellos y los juzga en sí mismos como dignos de ser reconocidos y estimados.” Por su parte, Dignitatis humanae, "no se limita a detectar y a juzgar sino que discierne ese signo 
específico de la libertad religiosa, expresión de la dignidad humana, tratando de asimilarlo a la luz de la Tradición viva, entroncándolo en el cuerpo total del depósito eclesial cristiano" (1969, p. 195). Esta es, entonces, la "actitud normativa teórico-práctica del Vaticano II: la Iglesia, lealmente enfrentada al mundo contemporáneo, trata de juzgar sus valores típicos y de asimilarlos en profundidad a su propia riqueza" (1969, p. 196).

A la luz de estas reflexiones, por contraste, el autor caracteriza las insuficiencias o ambigüedades graves que advierte en Medellín: "no logra evitar el mismo tipo de errores cometidos a raíz de Trento y del Vaticano I, aunque lo hace bajo un signo contrario. En efecto, la identificación abusiva de teoría y práctica se cristaliza esta vez en el dominio de la teoría por la praxis." La "consecuencia” o "resultado" que se sigue de allí "es una inevitable laxitud doctrinal en el orden de la evangelización” que, a su juicio, es "muchísimo más grave que todos los defectos prácticos que pudieran ocasionar Trento y el Vaticano I” (BRIANCESCO, 1969, p. 194).

Expongamos con un poco más de detalle el análisis de Briancesco. El núcleo de la crítica a "la metodología teológica básica" (BRIANCESCO, 1969, p. 225) de Medellín y al sentido de la categoría de signos de los tiempos es formulado con claridad en varias oportunidades: "la coyuntura concreta, los hechos, se constituyen en bases normativas de reinterpretación de las verdades de fe" (1969, p. 221)9, un "proceso de degradación mental" que convierte "los hechos en reguladores de los principios de fe", en otras palabras, "la realidad práctica se constituye en norma, no sólo de acción, sino de verdad teórica. Es el hombre concreto, en situación, quien fija el criterio de acción y, además, el de los valores y el de la verdad. Y, al traducir esto al terreno de la fe, el criterio de conducta y de

\footnotetext{
9 “El reiterado acento en la coyuntura histórica de América latina no sólo da la pauta del espíritu de los redactores del Documento sino que orienta la elección de cierto número de conceptos o nociones que, al ser refrendadas por miembros de un episcopado continental, adquieren derecho de ciudadanía en el terreno teológico. Estas categorías nos parecen depender de la expresión 'signos de los tiempos', condensarse en la de 'liberación' y multiplicarse en otras tantas que, abarcando los campos de la antropología, la cristología y la moral, dan relieve a los nuevos aspectos en que el hombre latinoamericano debe hoy pensar y vivir su existencia cristiana". (BRIANCESCO, 1969, p. 198-200).
}

Horizonte, Belo Horizonte, v. 16, n. 50, p. 517-543, maio/ago. 2018 - ISSN 2175-5841 
verdad cristianas”. La identificación abusiva de teoría y práctica que el autor había advertido en el caso de los otros concilios, no en ellos mismos si no en la praxis posterior a partir de algunas enseñanzas de dichas asambleas, aquí se cristaliza "en el dominio de la teoría, por la praxis” (1969, p. 222) ${ }^{10}$.

El mismo método de trabajo elegido, reflejado claramente en la estructura misma de los documentos, parece manifestar una actitud tal que, partiendo de lo concreto, encuentra en ello la norma a la luz de la cual ir iluminando los principios de fe para, en un tercer momento, aplicarlos a las conclusiones pastorales, que difícilmente escapan así a la opción singular concreta determinada en todos los campos invocados, desde el político hasta el económico social. Y ello en virtud de la fe cristiana, pero en cuanto iluminada, es decir, normada de hecho por las exigencias concretas preliminares. (BRIANCESCO, 1969, p. 197).

Una limitación importante que advierte Briancesco reside en que, en su opinión, en el documento de Medellín los sucesos históricos se convierten “automáticamente”, “por sí mismos”, en signos de los tiempos:

Es el hecho mismo el que, en última instancia, se constituye por sí mismo en "signo de los tiempos" y, así, en voz de Dios que interpela en la Historia. Bastará a lo sumo que tenga cierta densidad y repercusión inmediata en cualquier orden que sea (político, social, cultural...), para que, declarándolo auténticamente humano, ascienda automáticamente al rango prestigioso de "signo". (BRIANCESCO, 1969, p. 221).

De este modo, piensa, se utiliza una terminología de Juan XXIII y del Vaticano II, pero con una comprensión bien diversa. En su opinión esta limitación pertenece a "la lógica inherente a las declaraciones de Medellín” y, sin lugar a dudas, es "lo que extraen del Documento la mayoría de los que se apoyan constantemente en él” (1969, p. 221). Como se observa con claridad la crítica de Briancesco se dirige, ante todo, al mismo texto de Medellín -a su misma "lógica"- y no solo a algunas interpretaciones posteriores.

\footnotetext{
10 "La vieja ecuación: evangelizar=civilizar ha recobrado así actualidad. Con la diferencia, y la gravedad consiguiente, que tiene como andamio una construcción ideológica que se quiere cristiana, cuyo eje dominante parece consistir en la exaltación de lo empírico con todo su séquito: los hechos, la praxis, la eficacia, y, por supuesto, la sociología como irremplazable instrumento científico. La realidad práctica se constituye en norma, no sólo de acción, sino de verdad teórica". (BRIANCESCO, 1969, p. 222).
}

Horizonte, Belo Horizonte, v. 16, n. 50, p. 517-543, maio/ago. 2018 - ISSN 2175-5841 
Las unilateralidades recién apuntadas se verifican, en la opinión del teólogo argentino, en la debilidad que se detecta en la formulación de los criterios de discernimiento:

\begin{abstract}
...aunque se mencionan algunos principios eventuales de discernimiento (conciencia, fe,...), no se ve en ninguna parte, salvo error, un esfuerzo concreto de interpretación que muestre cómo, y mediante el recurso a qué principios o motivos, se va realizando la lectura de los hechos para encontrar entre ellos los auténticos "signos". Se percibe, por el contrario, cómo el recurso a la coyuntura histórica impone, es decir, norma, una nueva manera de pensar cristiana en función de la cual se debe orientar la acción pastoral. (BRIANCESCO, 1969, p. 221).
\end{abstract}

La consecuencia directa o el resultado que se obtiene con esta forma de proceder -el "dominio de la teoría, por la praxis"- es la "laxitud doctrinal en el orden de la misión evangelizadora de la Iglesia”. Refiere explícita y detenidamente a lo largo del artículo al empobrecimiento de categorías doctrinales clave en el ámbito de la cristología (BRIANCESCO, 1969, p. 214-216), en la concepción del pecado (1969, p. 211) y, sobre todo, en la noción de liberación ${ }^{11}$. La "consecuencia más grave y temible que revela el fondo de todo este proceso de degradación mental" se formula así:

Al erigir los hechos en reguladores de los principios de fe se cae necesariamente en una óptica doctrinal laxa de evangelización: la redención de Cristo, destrucción del pecado y de su efecto propio, la culpa, y sólo en esperanza del resto de sus secuelas, es reemplazada por una noción amplísima y ambigua de liberación, enteramente centrada en la desgraciada situación del hombre actual, fruto y pena de los pecados humanos, pero que según la doctrina teológica tradicional, solo secundariamente y en perspectiva interesa a la situación del cristiano salvado. (BRIANCESCO, 1969, p. 222).

Por otra parte, las críticas a una inadecuada relación entre desarrollo humano y crecimiento del Reino -se trataría de "una visión dinámicamente

\footnotetext{
11 “El saldo que arroja nuestro análisis de la categoría de 'liberación' no es pues favorable. En el mejor de los casos, aparece como una noción compleja, confusa, por lo mismo ambigua, olvidando o poniendo en la sombra verdades teológicas esenciales al cristianismo, como la Cruz y el pecado en su comprensión profunda." (BRIANCESCO, 1969, p. 212). Cf. el análisis más detenido en Briancesco (1969, p. 203). Por razones de espacio, no es objetivo de esta contribución analizar las categorías cristológicas, la noción de pecado y liberación del autor y en su relación con Medellín. Reconozco, no obstante, que para responder con mayor detalle a la objeción metodológica de Briancesco -los hechos se han convertido en reguladores de la fe- esa tarea sería necesaria.
}

Horizonte, Belo Horizonte, v. 16, n. 50, p. 517-543, maio/ago. 2018 - ISSN 2175-5841 
unitaria”, de "tipo monista"-(BRIANCESCO, 1969, p. 210, 206; 1977, p. 102-104)12 y a la carencia de un pluralismo político al exigir una determinada praxis aparecen en diversos contextos del artículo (BRIANCESCO, 1969, p. 197).

Un texto de Pablo VI del mismo año, de la audiencia general del 16 de abril de 1969 (PABLO VI, 1969), que, a juicio de Briancesco, muestra la manera adecuada de enfrentarse a la temática de los signos de los tiempos le sirve al autor como contrapunto correctivo a las falencias detectadas por él en el texto de Medellín: con Pablo VI destaca el carácter intrínsecamente ambiguo de los hechos históricos, la necesaria actitud crítica a la luz del evangelio, la tarea de descubrir el “sentido superior”, religioso, en lo "inmediatamente observable”, etc.

A la luz de las explicaciones ofrecidas por el teólogo argentino se comprende bien su negativa evaluación global de Medellín; en su opinión, muchas personas "confiesan francamente no ver sino muy laboriosa y dificultosamente su plena armonía con el Vaticano II y su perfecta correspondencia con la teología católica tradicional." Una actividad pastoral de cristianos y cristianas que se apoyan en la doctrina y en las orientaciones de Medellín, "como es notorio, crean por eso un público desconcierto en el orden de las ideas y el de la acción” (BRIANCESCO, 1969, p. 225).

\section{2 ¿Una exaltación de lo empírico? Hacia una evaluación más ponderada}

Una primera observación que puede hacerse en relación con las críticas metodológicas de Briancesco es un reconocimiento autocrítico, pero situado en su contexto temporal correspondiente. Indudablemente es posible detectar en la bibliografía de la época y también en el mismo texto de Medellín varias limitaciones, algunas de las cuales tienen que ver con la novedad en la forma de proceder al nivel teológico y magisterial en la década del 6o’. La cita de Gutiérrez

\footnotetext{
${ }^{12}$ Aunque con perspectivas diversas, tres autores de la época citados en esta contribución coincidirían en señalar la idea del "desarrollo integral" como "íntimamente ligado a la salvación" (GUTIÉRREZ, 1969, p. 15) como un tema central o quizás la temática central que recorre los textos de Medellín (MCGRATH, 1971, p. 170).
}

Horizonte, Belo Horizonte, v. 16, n. 50, p. 517-543, maio/ago. 2018 - ISSN 2175-5841 
de 1969, referida al inicio, que destaca que no estaban "acostumbrados" a este tipo de lenguaje no es una constatación pasajera. Pone de relieve una novedad recientemente asumida en Gaudium et spes en medio de debates y perplejidades muy notables. Como ha sido ya estudiado, varios de los mejores teólogos europeos de la época no podían dar cuenta argumentativamente del salto metodológico de la Constitución pastoral (Congar, Rahner, Ratzinger, Semmelroth, etc.) (TURBANTI, 2000, p. 638-643; SANDER, 2005, p. 838-853).

Por otra parte, no deben ocultarse ni minimizarse las insuficiencias metodológicas que pueden ser advertidas desde distintos puntos de vista en el mismo hecho de Medellín. Como ha sido observado con acierto, la carencia de textos y temas bíblicos y, en general, una impronta más importante desde esta perspectiva permanecerá como un déficit a lo largo de toda la Conferencia, incluido el documento final (BEOZZO, 1998, p. 846-849). Puede decirse que esta debilidad es común a una gran parte de los textos y discursos en torno a la Conferencia, incluidos, por ejemplo, los textos inaugurales de Pablo VI y de los cardenales J. Landázuri, A. Samoré y A. Brandao Vilela. La ponencia de E. Pironio, la segunda al inicio de la conferencia después de la de M. McGrath, es una excepción (PIRONIO, 1969). Una contribución reciente de P. Suess ofrece un esbozo interesante y provocador del aporte que otorga una mirada bíblica, neotestamentaria, cristológica y escatológica de los signos de los tiempos, concretada además desde América Latina (SUESS, 2015). Tiempos mesiánicos desde un lugar de clase podría titularse su reflexión que, por contraste, desnuda las limitaciones de los análisis bíblicos de muchos de los textos en torno a la Conferencia

Probablemente la debilidad bíblica del método de Medellín es deudora de la debilidad bíblica de la Constitución pastoral y de que el círculo hermenéutico Dei Verbum-Gaudium et spes, esto es, el vínculo intrínseco en la doble práctica del discernimiento de los signos de los tiempos y la de una lectura actual de la Biblia, es solo insinuado al final del Vaticano II, dejado como tarea al proceso de recepción conciliar posterior. El Concilio que ofreció su gran adquisición metodológica, 
probablemente también contagió sus insuficiencias en la forma teológica de proceder. En particular los trabajos de C. Theobald (2009, p. 314-315, 361, 420, 486, 514, 667, 691, 819; 2015, p. 247-259) en estos años muestran, precisamente, algunas de las limitaciones del paso adelante hecho en el Concilio, que es posible verificar también en los textos en torno a Medellín.

Desde otra perspectiva también pueden subrayarse limitaciones. Aunque no faltan esfuerzos verificables de conectar mediante un círculo hermenéutico los distintos momentos, del ver-juzgar-actuar, esta tarea aparece como necesitada de desarrollo. Debe reconocerse, no obstante, que más allá de Medellín dicha insuficiencia puede verificarse como permanente en las décadas siguientes y en las posteriores Conferencias generales del episcopado (LEGORRETA, 2015, p. 291292, 371, 376). Representa un uso superficial del instrumento que perjudica la profundización de los tres aspectos implicados en el procedimiento ${ }^{13}$. Sin embargo, la misma crítica de Briancesco - los hechos devienen norma y reguladores de la fe y determinan, empobreciendo unilateralmente, los contenidos de nociones teológicas importantes- indica que la mirada a la realidad por parte de los documentos de la Conferencia no constituye una mera descripción de fenómenos caracterizados de una manera inconexa con el momento del juzgar, con el conjunto del misterio cristiano.

También la densidad epistemológica de la praxis aparece como limitada en los textos en torno a Medellín. Una advertencia con lo sucedido con el método en la obra y la acción de J. Cardijn colabora a iluminar el asunto. A. Brighenti muestra cómo, a partir de la década de los años cincuenta, la trilogía se articulará más dialécticamente, en la medida en que el "obrar" pasará a ser "la mejor introducción al 'ver". En este sentido, expone Brighenti, Cardijn renuncia al primado de la

\footnotetext{
${ }^{13}$ Sin embargo, no faltan textos que muestran conciencia del asunto. Un ejemplo: "La toma de conciencia del mensaje cristiano se hace profundizando cada vez más en la comprensión auténtica de la verdad revelada. Pero esa toma progresiva de conciencia crece al ritmo de la emergencia de las experiencias humanas, individuales y colectivas. Por eso, la fidelidad de la Iglesia a la revelación tiene que ser y es dinámica. La catequesis no puede, pues, ignorar en su renovación los cambios económicos, demográficos, sociales y culturales sufridos en América Latina" (VIII, 5). Es interesante la utilización, en ese contexto hermenéutico, de la expresión "teología de la revelación", por única vez en Medellín (VIII, 6).
}

Horizonte, Belo Horizonte, v. 16, n. 50, p. 517-543, maio/ago. 2018 - ISSN 2175-5841 
doctrina, para partir realmente de la realidad, de la vida, lo cual produce un impacto importante sobre la misma "doctrina". La acentuación de un círculo hermenéutico conducirá a que, en la obra del autor belga, no se hable ya de "pasos” en el método, sino de "momentos" en una relación dialéctica, articulada desde el polo de la vida o de la realidad histórica (BRIGHENTI, 2015, p. 610-612) ${ }^{14}$. Hasta donde puedo ver con mis lecturas de textos de la época, una reflexión detenida de la metodología, como la que sugieren estas breves consideraciones, no estaría presente en la bibliografía del momento, ni en los documentos preparatorios oficiales, ni en la ponencia inaugural sobre signos de los tiempos de M. McGrath, tampoco en el texto de Medellín (SCHICKENDANTZ, 2017a).

La "reducción prevalentemente sociológica" de la categoría signos de los tiempos, observada en los debates del Vaticano II, como advierte G. Ruggieri, es posible detectarla también en la bibliografía posterior (RUGGIERI, 1999, p. 21 nota 18). Medellín no sería una excepción. En el marco de los debates de Gaudium et spes, en la cuarta sesión de 1965, con dicha noción se aludía a "fenómenos que por su difusión y por su gran frecuencia caracterizan una época y a través de los cuales encuentran expresión las necesidades y las aspiraciones de la humanidad actual"15. En el caso de Medellín es quizás en los textos de M. McGrath el lugar más autorizado para evaluar la comprensión del concepto en aquel momento. Como presidente de la sub-comisión de signos de los tiempos, el obispo panameño, luego vicepresidente del CELAM en 1968, fue el encargado de presentar a la asamblea conciliar, en el último período de sesiones, el informe oficial correspondiente a la parte introductoria del texto de la futura Constitución y de explicar el significado que asumía la categoría signos de los tiempos en el documento (SCHICKENDANTZ, 2013, p. 87-89, 97-101). McGrath en la Relatio circa Expositionem introductivam, advierte que “entre los cambios menores”, está el del inicio del número 4 que “declara más claramente” la necesidad que la Iglesia tiene

\footnotetext{
${ }^{14}$ Los trabajos de Brighenti ayudan a comprender la continuidad y la discontinuidad entre la pedagogía de la Acción católica, con su método ver-juzgar-actuar, y las construcciones teológicas posteriores (1994, p. 207-254).

${ }^{15}$ Expresión de François Houtart (perito conciliar belga), citado en (TURBANTI, 2000, p. 374).
} 
de "escrutar los signos de los tiempos e interpretarlos a la luz del Evangelio, ahora como en cualquier tiempo." Y añade: "Las palabras 'signos de los tiempos' utilizadas aquí por única vez, no lo son en sentido técnico, sino general, como se encuentra en varios documentos de los sumos pontífices Juan XXIII y Pablo VI” (Acta Synodalia Sacrosancti Concilii Vaticani II, IV/6, p. 564, cursiva mía, s/d). Acogía la preocupación manifestada, incluso por observadores ecuménicos, acerca del sentido preciso, escatológico, que la expresión tiene en la Biblia y, por tanto, diverso al del documento. En ese marco se comprenden mejor las reflexiones de la ponencia inaugural de McGrath en Medellín, "Los signos de los tiempos en América Latina hoy". Para caracterizar el concepto de signo de los tiempos distingue allí entre el "lenguaje bíblico" y la "otra forma, más actual", usada por Pacem in terris. Y aclara explícitamente: la Constitución "adoptó el término en este nuevo sentido" (MCGRATH, 1969, p. 75) ${ }^{16}$.

Pero si aquí es posible advertir la "reducción fenomenológica”, de la que habla Ruggieri y que, con otras palabras, observa Briancesco en Medellín, McGrath da un paso más en la conferencia inaugural. Los signos de los tiempos según la “otra forma, más actual” de Gaudium et spes es caracterizada, a su juicio, de esta manera: "son en sí aquellos grandes hechos, acontecimientos y actitudes o relaciones que caracterizan a una época.” Y, con una consideración que parece ir un poco más allá, al menos explícitamente, de sus propias expresiones en el Concilio, añade: "Proyectan su significado sobre dos niveles". El primero, que revelan "las corrientes subterráneas", “causas y efectos de los eventos”, "las esperanzas y preocupaciones" de los seres humanos. Por ello, quien comprende los signos "puede intuir y palpar... la corriente dinámica de su tiempo", "la historia que vive", así también "podrá mejor influir en ella”. El segundo nivel, refiere a la interpretación de la fe: el “creyente trata de intuir más a fondo”. "Creyendo en la

\footnotetext{
${ }^{16}$ A la subcomisión que presidía en el Concilio, "le competía estudiar la noción de 'signos de los tiempos', término usado en el documento a imitación de Juan XXIII" (MCGRATH, 1967, p. 172, cursiva mía). De manera análoga se expresa en 1996 y añade: "El concepto sugiere la investigación, el acercamiento al análisis social, la técnica del 'ver-juzgar-actuar' de los jocistas, que se ha hecho común en la Iglesia después del Concilio, ampliamente debido a su uso, si bien modificado en esta Constitución" (MCGRATH, 1996, p. 25).
}

Horizonte, Belo Horizonte, v. 16, n. 50, p. 517-543, maio/ago. 2018 - ISSN 2175-5841 
historia de la salvación, que se plasma en la historia del mundo, él se esfuerza para ver a través de esos signos y las corrientes temporales que revelan, al espíritu de Dios obrando en 'el mundo en que vivimos, sus esperanzas, sus aspiraciones y el sesgo dramático que con frecuencia le caracteriza'. Esto lo ha de hacer la Iglesia escrutando 'a fondo los signos de los tiempos e interpretándolos a la luz del Evangelio", concluye McGrath citando Gaudium et spes 4 (MCGRATH, 1969, p. 75-76, cursiva mía). Por tanto, si es posible observar que en los debates conciliares sobre la noción de signos de los tiempos se destacaba más su significado "fenomenológico" o "sociológico", por la pretensión de evitar las observaciones provenientes de la consideración de su significado bíblico, que en la dinámica de la disputa de entonces conducía a excluir el término de la futura Constitución, en la ponencia de Medellín aparece más explícitamente el “doble nivel”, empírico y teológico que, no obstante, no recoge la rica perspectiva que plantea su uso neotestamentario más preciso, esto es, cristológico, escatológico, mesiánico y kairológico (Mt 16,3).

Estas consideraciones parecen importantes para responder adecuadamente a las objeciones de Briancesco referidas más arriba. El teólogo argentino afirma que es "el hecho mismo el que, en última instancia, se constituye por sí mismo en 'signo de los tiempos' y, así, en voz de Dios que interpela en la Historia.” Por eso, aduce, que "bastará a lo sumo que tenga cierta densidad y repercusión inmediata en cualquier orden que sea (político, social, cultural...), para que, declarándolo auténticamente humano, ascienda automáticamente al rango prestigioso de "signo" (BRIANCESCO, 1969, p. 221). Por el contrario, en la explicación de McGrath hay una específica lectura teológica de los acontecimientos, un "doble nivel" que supone la autonomía y la vinculación adecuada de ambas lecturas. Y si es verdad que en algunos textos de Medellín la categoría “signos de los tiempos” aparece caracterizada en la línea de una "reducción prevalentemente sociológica"17, no

\footnotetext{
${ }^{17}$ Un ejemplo nítido puede apreciarse en el documento de Catequesis: "La catequesis se halla frente a un fenómeno que está influyendo profundamente en los valores, en las actitudes y la vida misma del hombre: los medios de comunicación social. Este fenómeno constituye un hecho histórico irreversible que en América Latina avanza rápidamente y conduce en breve plazo a una cultura universal: 'la cultura de la imagen'. Este es un signo de los tiempos que la Iglesia no puede ignorar" (VIII, 12).
}

Horizonte, Belo Horizonte, v. 16, n. 50, p. 517-543, maio/ago. 2018 - ISSN 2175-5841 
quedan dudas de que esos acontecimientos históricos necesitan una relectura teológica. Ellos no se convierten “automáticamente”, “por sí mismos”, “en voz de Dios que interpela en la Historia” como afirma Briancesco (1969, p. 221). Explícitamente se reclama un acto de interpretación. En el Mensaje a los pueblos de América Latina de la Conferencia se afirma:

A la luz de la fe que profesamos como creyentes, hemos realizado un esfuerzo para descubrir el plan de Dios en los 'signos de nuestros tiempos'. Interpretamos que las aspiraciones y clamores de América Latina son signos que revelan la orientación del plan divino operante en el amor redentor de Cristo que funda estas aspiraciones en la conciencia de una solidaridad fraternal.

Es indudable que la misma perspectiva general de Gaudium et spes y la categoría de dignidad humana, central en la comprensión de dicha Constitución, sirve de hecho aquí como un criterio de juicio decisivo.

Si estas consideraciones hacen frente a la crítica radical de Briancesco, una precisión conceptual importante está ausente en la bibliografía de la época. Las reflexiones de McGrath acerca del "doble nivel” de la categoría de signos de los tiempos, entre el "lenguaje bíblico" y la “otra forma, más actual”, recién referidas, tiene mucho relieve a la luz de las discusiones de entonces. Indican, no obstante, un asunto metodológico necesitado de una clarificación conceptual, particularmente en lo que atañe a la articulación de los dos niveles ${ }^{18}$. La problemática se visibiliza, en especial, cuando se formula el efecto del círculo hermenéutico en la revelación misma. McGrath afirma en su ponencia: "es así, que los signos de los tiempos nos llevan a decir cosas nuevas del Evangelio”, pero el límite de esa novedad se formula con claridad; "no en cuanto a él mismo, pero sí respecto de sus aplicaciones" (MCGRATH, 1969, p. 77). No solo la densidad epistemológica de la praxis aparece como limitada en los textos analizados, como se ha dicho, sino también la más exacta naturaleza de la densidad teológica del presente. La pregunta por el estatuto teológico de esta "novedad” y de lo que ella significa para la metodología

\footnotetext{
${ }^{18}$ Los trabajos de G. Ruggieri y P. Hünermann, por citar algunos de los mejores, pueden mostrar el salto de calidad que se ha dado en estas décadas en la comprensión del doble nivel (ético-histórico y como fenómeno teológico) (SCHICKENDANTZ, 2016b, p. 174).
}

Horizonte, Belo Horizonte, v. 16, n. 50, p. 517-543, maio/ago. 2018 - ISSN 2175-5841 
ocupa a la teología hasta hoy, permanece como una cuestión irresuelta (SCHICKENDANTZ, 2016b). La concepción de la praxis histórica como lugar teológico, por su parte, expresión metodológica central en la bibliografía latinoamericana posterior, está necesitada de una precisión ulterior (AQUINO JÚNIOR, 2010; COSTADOAT, 2015; 2016).

En cuanto a los criterios de discernimiento que Briancesco extraña en Medellín es posible individuar algunos ejemplos importantes. En el documento sobre los sacerdotes se afirma: "Reflexionaremos juntos apoyándonos en el don de Dios para discernir los signos de los tiempos. Encontraremos en el Evangelio la imagen más nítida de Cristo, el Señor” (XI, 28). Como se lee, se destaca claramente la fuente "más nítida” para el discernimiento. En el texto dedicado a la formación del clero hay otra formulación muy satisfactoria (XIII, 10). Allí el discernimiento de las "situaciones y exigencias de la comunidad", de "la realidad humana" se realiza con el apoyo de la Escritura, la experiencia litúrgica, en comunión de ejercicio con otros miembros del Pueblo de Dios -“con la ayuda del laicado”-, en unión con el obispo, con la asistencia del magisterio de la Iglesia y con las necesarias disposiciones personales, gracias también a una "purificación interior" que dispone a escuchar la Palabra; todo ello al servicio de un "saber juzgar aquellas realidades en relación con el plan de Dios". Se trata de una "tarea profética” realizada "a la luz de la fe"19. Es difícil encontrar en pocos renglones una descripción que incluya elementos teológicos tan amplios e importantes en orden a un discernimiento adecuado. Por otra parte, el documento de Medellín, sin ingenuidad, invita a “discernir los aspectos positivos y negativos que presenta en la actualidad” en más

\footnotetext{
19 "Se pide al sacerdote de hoy saber interpretar habitualmente, a la luz de la fe, las situaciones y exigencias de la comunidad. Dicha tarea profética exige, por una parte, la capacidad de comprender, con la ayuda del laicado, la realidad humana y, por otra, como carisma específico del sacerdote en unión con el obispo, saber juzgar aquellas realidades en relación con el plan de salvación. Para llegar a esta capacidad se necesita: a) Una profunda y continuada purificación interior que disponga al hombre para captar las auténticas exigencias de la Palabra de Dios (sentido de la dirección espiritual); b) Un "sensus fidei", que se profundiza particularmente por: la Sagrada Escritura asimilada vitalmente en la oración personal, en el estudio serio del Mensaje y en una activa, consciente y fructuosa participación en la liturgia [SC 17]; Una constante confrontación con las enseñanzas del magisterio de la Iglesia. Con el mismo fin, parece necesario desarrollar una fuerte pasión por la verdad y una disposición habitual para defenderse de la unilateralidad por medio de una búsqueda y verificación comunitaria" (XIII, 10). También en el texto sobre Catequesis es posible verificar una formulación explícita de criterios de discernimientos "a la luz" de los cuales "deben ser interpretadas seriamente" las "situaciones históricas y las aspiraciones auténticamente humanas" que, se afirma, "forman parte indispensable del contenido de la catequesis" (VIII, 6). La crítica de Briancesco a este texto parece injusta (1969, p. 207). Otro párrafo, también digno de notar desde esta perspectiva, se advierte en el documento de Catequesis (VIII, 15).
}

Horizonte, Belo Horizonte, v. 16, n. 50, p. 517-543, maio/ago. 2018 - ISSN 2175-5841 
de una oportunidad $(\mathrm{V}, 13)$. Incluso denuncia la "falta de equilibrio para discernir lo positivo de lo negativo en las novedades que surgen dentro de la vida de la Iglesia y del mundo” (XIII, 4), en clara alusión a una asunción acrítica de valores ambientales. Parece que la tarea demandada por Briancesco referida más arriba - discernir e integrar, juzgar y asimilar en la propia tradición- es también una preocupación de los protagonistas de Medellín.

En todo este análisis no debería perderse de vista un argumento importante. Briancesco opone el Vaticano II a Medellín; aquel habría ofrecido una claridad conceptual en lo metodológico que en la Conferencia no se advierte. Pero los estudios recientes más informados dejan a la luz las múltiples insuficiencias que contiene Gaudium et spes. Además de la "reducción prevalentemente sociológica” ya apuntada, la misma Constitución pastoral "no ofrece ninguna explicación adecuada de los signos de los tiempos" (RUGGIERI, 1999, p. 21 nota 18). Dos limitaciones centrales, al menos, se explicitan nítidamente en los trabajos de Ruggieri y en otros autores, por ejemplo: por una parte, la "carencia de una adecuada hermenéutica histórica", por otra, "la carencia de una apropiada hermenéutica teológica” (RUGGIERI, 2017, p. 224). Desde la primera perspectiva, Gaudium et spes reconoce el aspecto positivo de la historia vivida, con la visión educada gracias a las intervenciones de Juan XXIII, pero trata la historia solo bajo el ángulo del progreso. Ruggieri argumenta, también, que el texto aparece unilateralmente determinado por "el entonces dominante horizonte hermenéutico antropocéntrico” (2006, p. 229-231). Desde el ángulo teológico, lo que se extraña, particularmente, es el enfoque mesiánico: la presencia del Mesías Jesús en la historia, perspectiva de los signos de los tiempos a reconocer como lo sugieren Mateo y Lucas. "Por tanto, la pregunta a la cual responder es: ¿la historia vivida de los seres humanos revela signos de la presencia del Mesías?” (RUGGIERI, 2017, p. 224). Es la cuestión del "significado teológico hermenéutico" de la categoría, "una hermenéutica de la historia bajo el signo de la esperanza mesiánica” (RUGGIERI, 2017, p. 220). También a la luz de los importantes trabajos de C. Theobald (2015, p. 
220) no es posible idealizar los resultados en el Vaticano II, particularmente en Gaudium et spes.

Con la perspectiva de hoy, se advierte que, en la década de los años sesenta, estaba recién a los inicios "una forma relativamente nueva de teología, no ya deductiva y abstracta sino inductiva y concreta” (CONGAR, 1970, p. 14), para la que los actores de la época no estaban "acostumbrados” (Gutiérrez). Lo formuló breve pero nítidamente Marcos McGrath, probablemente con una precisión mayor que la de muchos de sus colegas europeos de entonces, en un importante texto suyo (MCGRATH, 1966; SCHICKENDANTZ, 2013, 87-89). Allí alude McGrath a la disputa acerca del método que, según "los teólogos llamados progresistas”, refiere a los que habían redactado Lumen gentium, "debía proceder de acuerdo con el método teológico aceptado, lo que significaba partir de los principios de la revelación, que derivan de las normas de la fe y de la moral, aun para el orden temporal.” Esto es, un procedimiento que subordina unilateralmente lo práctico a lo teórico, lo pastoral a lo doctrinal. Por el contrario, afirma, había que "proyectar un nuevo método para este nuevo tipo de documento. Es este nuevo método, desarrollado y perfeccionado muy lentamente, imperfecto aún en el último borrador de la Constitución, el que el lector debe captar si quiere interpretar bien dicha Constitución” (MCGRATH, 1966, p. 496, cursiva mía).

En este sentido las preguntas metodológicas de Briancesco, independientemente de sus respuestas, se contextualizan mejor y muestran que, en aquel momento, el asunto era verdaderamente complejo, tanto en lo que se refiere a la exacta naturaleza de esta transformación, como en su relación con la forma de proceder teológica anterior, "el método teológico aceptado" en palabras de McGrath. Escribe Briancesco, “¿cuál es la metodología teológica básica, empleada por los redactores del Documento? ¿Cuál es su valor? ¿Cuál su relación con la teología tradicional?” (1969, p. 225). Estaba en cuestión y desarrollo, precisamente, una reforma en la manera de pensar la fe, en la metodología teológica que, entre otros aspectos, reformulaba de manera importante la relación entre teología y 
pastoral. Los esbozos de la obra señera de G. Gutiérrez, Teología de la liberación, con la búsqueda de "una nueva manera de hacer teología” ya estaban en desarrollo en ese tiempo (GUTIÉRREZ, 1971, p. 33). También en las reflexiones menos sistemáticas de Lucio Gera en aquel momento se advierte el impacto del "método empleado para la elaboración de la constitución pastoral Gaudium et spes”, para el que una "simple actitud empirista" no es suficiente; "es necesario un acto de interpretación”, “un acto de pensamiento y reflexión, de racionalización o, dicho de otro modo, una interpretación de la realidad que ha de hacerse a la luz de la fe y del Evangelio y utilizando los métodos científicos actuales" (GERA, 2015b, p. 59, 57) ${ }^{20}$. Las novedades para la historia de la Iglesia que representan un concilio pastoral, una constitución pastoral y un momento inductivo en la forma teológica de proceder estaban en juego -incluso todavía hoy- en estos debates.

Debe advertirse con claridad lo que había sucedido en el marco de pocos años. J. O. Beozzo ha advertido que "en el método, (está) el secreto de Medellín” (1998, p. 828). Y en 2008 escribió: "El método, Ver, Juzgar y Actuar, heredado de la JOC de Joseph Cardijn, se inspiró también en la teología de los 'Signos de los Tiempos' de Gaudium et spes y fue el hilo conductor de todos los trabajos de Medellín” (BEOZZO, 2008). Una importante novedad eclesial y teológica, introducida con muchas dificultades al final del Concilio en solo uno de sus documentos (1965), poco después, en 1968, se convertía en "hilo conductor” de la Conferencia de Medellín.

\footnotetext{
${ }^{20}$ En el caso argentino, el uso del método de la JOC (ver-juzgar-actuar) es posible verificarlo en diversas iniciativas eclesiales de la época: en el Movimiento Rural de Acción Católica, en la Juventud Universitaria Católica, en el Movimiento de Sacerdotes para el Tercer Mundo (POLITI, 1992, p. 129, 134, 175). Sobre este último Movimiento, afirma Politi (1992, 175): “Un importante aporte fue el método pastoral (...) En este sentido, los Sacerdotes para el Tercer Mundo pusieron en práctica, ya en 1968, lo que luego sería el modo de pensar y actuar pastoralmente formulado por la Teología de la Liberación".
}

Horizonte, Belo Horizonte, v. 16, n. 50, p. 517-543, maio/ago. 2018 - ISSN 2175-5841 


\section{REFERENCIAS}

Acta Synodalia Sacrosancti Concilii Vaticani II. Ciudad del Vaticano: 1970-1999, v. 6, p. 563-565.

AQUINO JÚNIOR, Francisco de. Justicia. In: GODOY, M.; AQUINO JÚNIOR, F. (Org.). 50 anos de Medellín. Revisitando os textos, retomando o caminho. São Paulo: Paulinas, 2017. p. 42-57.

AQUINO JÚNIOR, Francisco de. Sobre o conceito 'lugar teológico'. Revista Eclesiástica Brasileira, Petrópolis, n. 278, p. 451-453, 2010.

BEOZZO, José Oscar. Medellín: inspiração e raízes. Revista Eclesiástica Brasileira, Petrópolis, n. 232, p. 822-850, 1998.

BEOZZO, José Oscar. Medellin: Quarenta annos. Disponible en: <http://www.catedralsaojose.org.br/catedral2011/reflexao/2534-medellin,-quarentaanos:-1968-2008.html>. Acceso en: marzo 2018.

BRIANCESCO, Eduardo. En torno a la Evangelii nuntiandi. Apuntes para una teología de la evangelización. Teología, Buenos Aires, n. 30, p. 101-134, 1977.

BRIANCESCO, Eduardo. Medellín: un caso de teología y pastoral. Teología, Buenos Aires, n. 15-16, p. 188-227, 1969.

BRIGHENTI, Agenor. Documento de Aparecida: o texto original, o texto oficial e o Papa Francisco. Revista Pistis \& Práxis, Paraná, vol. 8, n. 3, p. 673-713, 2016.

BRIGHENTI, Agenor. Método ver-julgar-agir. In: DECIO PASSOS, J.; LOPES SANCHEZ, W. (Ed.). Dicionário do Concílio Vaticano II. São Paulo: Paulinas, 2015. p. 608-615.

BRIGHENTI, Agenor. Raíces de la epistemología y del método en la teología latinoamericana. Medellín, Bogotá, n. 78, p. 207-254, 1994.

CONGAR, Yves y otros. La respuesta de los teólogos. Buenos Aires: Ediciones Carlos Lohlé, 1970.

COSTADOAT, Jorge. El 'lugar teológico' en Jon Sobrino. Theologica Xaveriana, Bogotá, n. 181, p. 23-49, 2016.

COSTADOAT, Jorge. La historia como 'lugar teológico' en la Teología latinoamericana de la liberación. Perspectiva teológica, Belo Horizonte, n. 132, p. 179-202, 2015.

GALLI, Carlos. Eduardo Briancesco: la fiesta del pensar. Teología, Buenos Aires, n. 83, p. 95-108, 2004. 
GERA, Lucio. Apuntes para una interpretación de la Iglesia argentina (1970).

In: GERA, Lucio. La teología argentina del pueblo. Santiago de Chile: Ediciones Universidad Alberto Hurtado, 2015a. p. 79-180.

GERA, Lucio. La Iglesia y el mundo (1967). In: GERA, Lucio. La teología argentina del pueblo. Santiago de Chile: Ediciones Universidad Alberto Hurtado, 2015b. p. 54-67.

GONZÁLEZ, Marcelo. La reflexión teológica en Argentina (1962-2004). Apuntes para un mapa de sus relaciones y desafíos hacia el futuro. Córdoba: EDUCC, 2004.

GUTIÉRREZ, Gustavo. El tiempo dirá si los textos de Medellín son letra muerta. CELAM, Bogotá, vol. 2, n. 19, p. 14-15, 1969.

GUTIÉRREZ, Gustavo. Teología de la liberación. Lima: Perspectivas, CEP, 1971.

LEGORRETA, José. Cambio e identidad de la Iglesia en América Latina. Itinerario de la eclesiología de comunión de Medellín a Aparecida. México D.F.: Universidad Iberoamericana, 2015. (edición electrónica).

MCGRATH, Marcos. A Living Theology in Latin America. The Review of Politics, Cambridge, vol. 33, n. 2, p. 163-171, 1971.

MCGRATH, Marcos. El Concilio Vaticano y el futuro. Medellín, Bogotá, n. 86, p. 11-35, 1996.

MCGRATH, Marcos. La génesis de Gaudium et spes. Mensaje, Santiago de Chile, n. 153, 495-502, 1966.

MCGRATH, Marcos. Los signos de los tiempos en América Latina hoy. In: CELAM (Ed.). La Iglesia en la actual transformación de América Latina a la luz del Concilio. I. Ponencias. Bogotá: Secretariado General del CELAM, 1969. p. 75-100.

MCGRATH, Marcos. Notas históricas sobre la Constitución Pastoral Gaudium et spes. In: BARAÚNA, G. (Ed.). La Iglesia en el mundo de hoy. Madrid: Studium ediciones, 1967. p. 165-181.

MOYANO, Mercedes. La Iglesia argentina en la década del sesenta. In: DUSSEL, E. y otros. Historia general de la Iglesia en América Latina. IX Cono sur. Salamanca:

Sígueme, 1994. p. 529-540.

PABLO VI. Udienza generale. Mercoledì, 16 aprile 1969. Disponible en:<http://w2.vatican.va/content/paul-vi/it/audiences/1969/documents/hf_pvi_aud_19690416.html.>. Acceso en: marzo. 2018.

PIRONIO, Eduardo. Interpretación cristiana de los signos de los tiempos hoy en América Latina. In: CELAM (Ed.). La Iglesia en la actual transformación de América Latina a la luz del Concilio. I. Ponencias. Bogotá: Secretariado General del CELAM, 1969, p. 101-122.

Horizonte, Belo Horizonte, v. 16, n. 50, p. 517-543, maio/ago. 2018 - ISSN 2175-5841 
POLITI, Sebastián. Teología del pueblo. Una propuesta argentina para Latinoamérica. Buenos Aires: Editorial Guadalupe, 1992.

RUGGIERI, Giuseppe. Chiesa sinodale. Bari-Roma: Editoti Laterza, 2017.

RUGGIERI, Giuseppe. Para una hermenéutica del Vaticano II. Concilium, Madrid, n. 279, p. 13-28, 1999.

RUGGIERI, Giuseppe. Zeichen der Zeit. Herkunft und Bedeutung einer christlichhermeneutischen Chiffre der Geschichte. In: HÜNERMANN, P. (Ed.). Das Zweite Vatikanische Konzil und die Zeichen der Zeit heute. Freiburg i.Br: Herder, 2006, p. 61-70.

SANDER, Hans-Joachim. Theologischer Kommentar zur Pastoralkonstitution über die Kirche in der Welt von heute Gaudium et spes. In: HÜNERMANN, P.; HILBERATH, B-J. (Ed.). Herders Theologischer Kommentar zum Zweiten Vatikanischen Konzil. Band 4. Freiburg i.Br: Herder, 2005, p. 581-886.

SCATENA, Silvia. De Medellín a Aparecida: la "lección" de una experiencia regional para una búsqueda de formas y estilos de colegialidad efectiva. In: SPADARO, A; GALLI, C. M. (Ed.). La reforma y las reformas en la Iglesia. Sal Terrae, Maliaño Cantabria, 2016. p. 273-293.

SCATENA, Silvia. In populo pauperum. La Chiesa latinoamericana dal Concilio a Medellín (1962-1968). Bologna: Il Mulino, 2007.

SCHICKENDANTZ, Carlos. ¿Una transformación metodológica inadvertida? La novedad introducida por Gaudium et spes en los escritos de Joseph Ratzinger. Teología y Vida, Santiago, n. 57, p. 9-37, 2016a.

SCHICKENDANTZ, Carlos. El teologar sinodal. Interacción dialéctica de lugares teológicos y sujetos eclesiales. Cristianesimo nella storia, Bologna, vol. 39, 2018b.

SCHICKENDANTZ, Carlos. La naturaleza teológica del momento inductivo. En tiempos de diversidad, pluralismo y alteridad cultural. Veritas, Valparaíso, n. 38, p. 99-120, 2017 b.

SCHICKENDANTZ, Carlos. Un cambio en la ratio fidei. Asociación (aparentemente ilícita) entre principios teológicos y datos empíricos. Teología y Vida, Santiago, n. 57, p. 157184, 2016b.

SCHICKENDANTZ, Carlos. Un enfoque empírico-teológico. En el método, el secreto de Medellín. Teología y Vida, Santiago, n. 58, p. 421-445, $2017 a$.

SCHICKENDANTZ, Carlos. Un nuevo capítulo de epistemología teológico-pastoral. Aportes a la comprensión de los signos de los tiempos. Atualidade Teológica, Rio de Janeiro, n. 58, p. 133-158, 2018a.

SCHICKENDANTZ, Carlos. Una elipse con dos focos. Hacia un nuevo método teológico a partir de Gaudium et spes. Teología, Buenos Aires, n. 110, p. 85-109, 2013.

Horizonte, Belo Horizonte, v. 16, n. 50, p. 517-543, maio/ago. 2018 - ISSN 2175-5841 
SUESS, Paulo. Sinais dos tempos. In: DECIO PASSOS, J.; LOPES SANCHEZ, W. (Ed.). Dicionário do Concílio Vaticano II. São Paulo: Paulinas, 2015• p. 895-901.

THEOBALD, Christoph. La réception du concile Vatican II. Accéder à la source. Paris: Cerf, 2009.

THEOBALD, Christoph. Le concile Vatican II. Quel avenir? Paris: Cerf, 2015.

TURBANTI, Giovanni. Un Concilio per il mondo moderno. La redazione della costituzione pastorale Gaudium et spes del Vaticano II. Bologna: Il Mulino, 2000. p. 638643 . 